ThIRST, M. L. (1957). J. gen. Microbiol. 17, 390-395

\title{
Hippurate Hydrolysis in Klebsiella-Cloaca Classification
}

\author{
By MERIEL L. THIRST \\ National Collection of Type Cultures, Colindale Avenue, London, N.W.9
}

\begin{abstract}
SUMMARY : 169 strains of Klebsiella pneumoniae and 68 strains of Cloaca cloacae were used in an examination of Hajna \& Damon's hippurate test and various modifications of it. The addition of a pH indicator (phenol red) to the medium enabled hydrolysis to be detected by a change of colour. Clear-cut distinction between $K$. pneumoniae and $C$. cloacae was not obtained with any method, but the indicator medium gave the best results and was simplest.
\end{abstract}

Hydrolysis of sodium hippurate was used by Hajna \& Damon (1934) to confirm the distinction, based on gelatin liquefaction, between Aerobacter aerogenes and $A$. cloacae. With a chemically defined medium containing sodium hippurate as the sole organic source of carbon, hydrolysis was shown by growth and could be confirmed by precipitating the resulting benzoate with a ferric chloride reagent. Other methods of detecting the hydrolysis of hippurate are the use of a pyridine + copper sulphate reagent (Munch-Petersen, 1940), or the observation of an increase in $\mathrm{pH}$ value (Cowan, 1955). Although Hajna \& Damon claimed reliable separation between $A$. aerogenes and $A$. cloacae, the use of their test has not been widely reported; consequently there is little further evidence about its value in distinguishing between these species. Recently there has been a tendency to separate Aerobacter aerogenes from $A$. cloacae and to place them in different groups or genera. Their long association in the same genus makes workers reluctant, without good evidence, to accept this separation; therefore the hippurate test was re-examined and a comparison was made between tests with Hajna \& Damon's medium and Cowan's micromethod. In the course of this comparison modifications were made to obtain better correlation between the hippurate tests and other criteria used in distinguishing these groups.

\section{METHODS}

Organisms. The strains used were those kept in the National Collection of Type Cultures (NCTC). Aerobacter aerogenes, which is commonly found in water, has the same cultural characters and reactions as most strains of Klebsiella pneumoniae although some of the latter may be atypical in their inability to produce gas from glucose, and in their MR and VP reactions. However, in general the two species are so similar that most workers now regard $A$. aerogenes as a later synonym of $K$. pneumoniae (Report, 1954) the name used in this paper. Two other species of Klebsiella are recognized, $K$. ozaenae and $K$.rhinoscleromatis. When $A$. aerogenes, the type species of Aerobacter, is removed the genus ceases to exist and another name must be 
found for $A$. cloacae; I shall use the name Cloaca cloacae. The Aerobacter type of paracolon, or 32011 type of Stuart, Wheeler, Rustigian \& Zimmerman (1943), is referred to as Hafnia alvei. Table 1 shows the characteristics which distinguish the various species.

Table 1. Distinguishing characters of the Klebsiella-Cloaca-Hafnia groups

$\begin{array}{lcccccc}\quad \begin{array}{c}\text { Klebsiella } \\ \text { Chino- }\end{array} & \text { Klebsiella } & \begin{array}{c}\text { Klebsiella } \\ \text { Character }\end{array} & \begin{array}{c}\text { scleromatis } \\ \text { ozaenae }\end{array} & \begin{array}{c}\text { Aerobacter } \\ \text { aerogenes }\end{array} & \begin{array}{c}\text { Cloaca } \\ \text { cloacae }\end{array} & \begin{array}{c}\text { Hafnia } \\ \text { alvei }\end{array} \\ \text { Lysine decarboxylase } & - & - & + & \mathbf{n r} & - & + \\ \text { Ornithine decarboxylase } & - & - & - & \mathbf{n r} & + & + \\ \text { Arginine decarboxylase } & - & - & - & \mathbf{n r} & + & + \\ \text { Koser's citrate } & - & + & + & + & + & + \\ \text { Urease } & - & \mathbf{d} & + & + & + & + \\ \text { Methyl-red } & + & + & - & - & + & + \\ \text { Voges-Proskauer } & - & - & + & + & + & + \\ \text { Gluconate } & - & - & + & \mathbf{n r} & + & + \\ \text { Malonate } & + & - & + & + & + & + \\ \text { Motility } & - & - & - & - & + & + \\ \text { Gelatinase } & - & - & - & - & (+) & - \\ \text { Gas from glucose } & - & \mathbf{d} & + & + & + & + \\ \text { Acid from lactose } & - & (+) & + & + & \mathbf{d} & + \\ \text { Gas from glycerol } & - & + & + & + & - & (+)\end{array}$

$+=$ positive in $1-2$ days; $(+)=$ weak or delayed positive; $-=$ negative; $d=$ different strains, each consistent in itself, give different reactions; $\mathrm{nr}=$ not recorded.

Media. The defined medium (HD) was prepared by Hajna \& Damon's (1934) method and a modified form (A) was made up as follows: $\mathrm{NaCl}, 0.5 \mathrm{~g}$.; $\mathrm{MgSO}_{4} .7 \mathrm{H}_{2} \mathrm{O}, 0 \cdot 02$ g.; $\mathrm{NH}_{4} \mathrm{H}_{2} \mathrm{PO}_{4}, 0 \cdot 1$ g.; $\mathrm{K}_{2} \mathrm{HPO}_{4}, 0 \cdot 1 \mathrm{~g}$.; sodium hippurate, 0.3 g.; agar (New Zealand), 1.0 g.; $4 \%$ (w/v) aqueous phenol red, $0.25 \mathrm{ml}$.; water, $100 \mathrm{ml}$. The medium, used in the form of slopes, was not cleared, and the final $\mathrm{pH}$ value $(6 \cdot 8-7 \cdot 0)$ needed little or no adjustment. Sterilization was by autoclaving at $15 \mathrm{lb}$./sq.in for $15 \mathrm{~min}$.

Detection of hydrolysis. Media HD and A were inoculated lightly from an overnight culture on nutrient agar. Medium HD was incubated for 5 days at the optimum temperature of the organism; after this it was examined for growth and two methods of testing for hydrolysis were used: (1) the ferric chloride test described by Hajna \& Damon (1934); (2) the pyridine + copper sulphate test with Zwikker's (1931) reagent described by Munch-Petersen (1940).

Medium A was inspected at intervals during an incubation period of 7 days. In 1-2 days sodium hippurate decomposition was shown by slight growth and a pink colour which increased with further incubation until the entire medium was alkaline. A few late positives (3-7 days) were found. A fairly heavy inoculum did not give false positive results, but a light inoculum was preferred since it did not obscure early signs of growth. The microtest was performed by Cowan's (1955) method with bromothymol blue as the indicator. 


\section{RESULTS}

Hajna \& Damon's original method was compared with the modified method (using medium A) and with the microtest, using as test organisms 200 strains of Klebsiella and 68 strains of Cloaca. Munch-Petersen's method was tested on a smaller number of strains (series a, Table 2). The results are summarized in Table 2, which shows that, on HD medium, the ferric chloride and pyridine +

Table 2. Comparison of tests for hydrolysis of hippurate

\begin{tabular}{|c|c|c|c|c|c|c|c|c|}
\hline \multirow{3}{*}{$\begin{array}{l}\text { Species and no. of } \\
\text { strains tested in } \\
\text { each series }\end{array}$} & \multirow[b]{3}{*}{ Result } & \multicolumn{4}{|c|}{ Series a } & \multicolumn{3}{|c|}{ Series b } \\
\hline & & \multicolumn{2}{|c|}{ Medium HD } & \multicolumn{2}{|c|}{ Alkalinity in } & \multirow{2}{*}{$\begin{array}{l}\text { Medium } \\
\mathrm{HD} \\
\mathrm{FeCl}_{3}\end{array}$} & \multicolumn{2}{|c|}{ Alkalinity in } \\
\hline & & $\mathrm{FeCl}_{3}$ & Pyr.-CuSO 4 & Medium A & Microtest & & Medium A & Microte \\
\hline $\begin{array}{l}\text { Klebsiella pneumoniae: } \\
\text { a, 157; b, } 12\end{array}$ & + & $\begin{array}{r}108 \\
49\end{array}$ & $\begin{array}{r}105 \\
52\end{array}$ & $\begin{array}{r}126 \\
31\end{array}$ & $\begin{array}{r}120 \\
37\end{array}$ & $\begin{array}{l}6 \\
6\end{array}$ & $\begin{array}{l}6 \\
6\end{array}$ & $\begin{array}{l}6 \\
6\end{array}$ \\
\hline $\begin{array}{l}\text { Cloaca cloacae: } \\
\text { a, } 45 ; b, 23\end{array}$ & 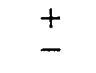 & $\begin{array}{r}4 \\
41\end{array}$ & $\begin{array}{r}4 \\
41\end{array}$ & $\begin{array}{r}0 \\
45\end{array}$ & $\begin{array}{l}13 \\
32\end{array}$ & $\begin{array}{r}0 \\
23\end{array}$ & $\begin{array}{r}\mathbf{0} \\
\mathbf{2 3}\end{array}$ & $\begin{array}{r}\mathbf{0} \\
\mathbf{2 3}\end{array}$ \\
\hline $\begin{array}{r}\text { K. ozaenae: } \\
\text { a, } 10 ; b, 6\end{array}$ & $\begin{array}{l}+ \\
-\end{array}$ & $\begin{array}{r}0 \\
19\end{array}$ & $\begin{array}{r}0 \\
19\end{array}$ & $\begin{array}{r}0 \\
19\end{array}$ & $\begin{array}{r}4 \\
15\end{array}$ & $\begin{array}{l}\mathbf{0} \\
\mathbf{6}\end{array}$ & $\begin{array}{l}\mathbf{0} \\
6\end{array}$ & $\begin{array}{l}\mathbf{0} \\
\mathbf{6}\end{array}$ \\
\hline $\begin{array}{l}\text { K. rhinoscleromatis: } \\
\mathrm{a}, 0 ; \mathrm{b}, 6\end{array}$ & $\begin{array}{l}+ \\
-\end{array}$ & $\cdot$ & $\dot{r}$ & · & · & $\begin{array}{l}\mathbf{0} \\
6\end{array}$ & $\begin{array}{l}0 \\
6\end{array}$ & $\begin{array}{l}0 \\
6\end{array}$ \\
\hline $\begin{array}{c}\text { Hafnia alvei: } \\
\text { a, } 0 ; b, 18\end{array}$ & $\begin{array}{l}+ \\
-\end{array}$ & . & . & . & $\dot{.}$ & $\begin{array}{r}0 \\
18\end{array}$ & $\begin{array}{r}0 \\
18\end{array}$ & $\begin{array}{r}12 \\
6\end{array}$ \\
\hline
\end{tabular}

copper sulphate tests gave similar results, but that for the Klebsiella strains these reagents were not as sensitive indicators of hydrolysis as was the development of alkalinity. Of the two tests based on the observation of $\mathrm{pH}$ value, medium $\mathbf{A}$ and the microtest, both gave essentially similar results, but the microtest was positive with 13 Cloaca strains and thus appeared to be less satisfactory for distinguishing organisms of the two groups.

\section{DISCUSSION}

The ferric chloride test depends on the relative solubilities of benzoate and hippurate in a solution of a ferric salt; the final concentration of iron is critical and measurement of both the culture fluid and the reagent is required. Munch-Petersen's method, consisting of the addition of Zwikker's reagent to an acid ether extract of the culture fluid, does not require accurate measurements; on the other hand, the preparation of the extract may be difficult with slimy cultures as these form emulsions with ether. Bacterial slime may also affect the microtest because it cannot be adequately separated from the bacterial cells, and the resultant light and badly washed suspensions may give false results. Doubtful results may be confirmed by testing chromatographically for the glycine liberated by the hydrolysis. Medium $\mathbf{A}$ has the advantage that it is unaffected by slime and the progress of the reaction may be observed throughout the test period. In contrast, both the tests on HD 
medium require the addition of reagents to the culture, which rules out repeated tests on the same culture.

The value of hippurate hydrolysis for distinguishing different species was assessed on medium $\mathbf{A}$ which gave sharper distinction than the microtest. Cloaca cloacae (68 strains), Klebsiella ozaenae (25), K. rhinoscleromatis $(6)$ and Hafnia alvei (18) were consistently hippurate-negative, but $K$. pneumoniae

Table 3. Comparison of hippurate reaction with other biochemical reactions and serotype of Klebsiella pneumoniae strains

\begin{tabular}{|c|c|c|c|c|c|c|c|c|c|c|c|c|c|}
\hline \multirow[b]{3}{*}{ Serotype } & \multicolumn{10}{|c|}{ Reaction } & \multirow{2}{*}{\multicolumn{3}{|c|}{$\begin{array}{c}\text { No. of strains } \\
\text { and } \\
\text { hippurate reaction }\end{array}$}} \\
\hline & \multirow{2}{*}{ 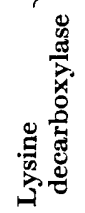 } & \multirow{2}{*}{ 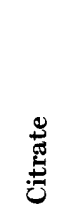 } & \multirow{2}{*}{ 岕 } & \multirow[b]{2}{*}{$\underline{z}$} & \multirow[b]{2}{*}{$\stackrel{s}{5}$} & \multirow{2}{*}{ 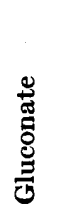 } & \multirow{2}{*}{ 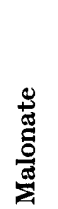 } & \multirow{2}{*}{ 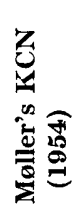 } & \multirow{2}{*}{$\frac{\mathscr{0}}{\overparen{0}}$} & \multirow{2}{*}{ 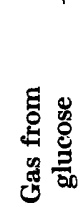 } & & & \\
\hline & & & & & & & & & & & + & $(+)$ & - \\
\hline \multirow[t]{7}{*}{$\mathbf{1}$} & + & + & + & - & + & + & + & + & - & + & $\mathbf{0}$ & 0 & $\mathbf{3}$ \\
\hline & - & - & + & - & + & + & - & + & - & - & 0 & 0 & 1 \\
\hline & + & - & + & - & + & + & + & + & - & - & o & 1 & 1 \\
\hline & + & + & + & + & - & + & + & + & - & + & o & 2 & 0 \\
\hline & + & + & + & + & - & + & + & + & - & - & 0 & 1 & 0 \\
\hline & + & + & + & - & + & + & - & + & - & + & o & 1 & 1 \\
\hline & + & + & + & - & + & + & + & + & - & - & 0 & 0 & 1 \\
\hline \multirow[t]{6}{*}{2} & + & + & + & - & + & + & + & + & - & + & 13 & 0 & 0 \\
\hline & - & - & + & - & + & + & + & + & - & + & 1 & 0 & 0 \\
\hline & + & - & + & - & + & + & + & + & - & + & 0 & 0 & 1 \\
\hline & + & - & + & - & + & + & + & + & - & - & 1 & 0 & 2 \\
\hline & + & + & + & - & + & + & - & + & - & - & 1 & 0 & 0 \\
\hline & + & + & + & - & + & + & + & + & - & - & 1 & 0 & o \\
\hline \multirow[t]{3}{*}{3} & + & + & + & + & - & - & + & - & - & + & o & 6 & 0 \\
\hline & + & + & + & + & - & + & + & - & - & + & 0 & 1 & 0 \\
\hline & + & + & + & + & - & - & + & + & - & + & 0 & 1 & 0 \\
\hline \multirow[t]{2}{*}{4} & + & + & + & - & + & + & + & + & - & + & 2 & 0 & 1 \\
\hline & + & - & + & - & + & + & + & + & - & + & 1 & 0 & 0 \\
\hline \multirow[t]{2}{*}{5} & + & - & + & - & + & + & + & + & - & + & 1 & 0 & 0 \\
\hline & + & + & + & + & - & + & + & + & - & + & 1 & 0 & 0 \\
\hline \multirow[t]{2}{*}{6} & + & + & + & - & + & + & + & + & - & + & 0 & 0 & 1 \\
\hline & + & - & + & - & + & + & + & + & - & + & 3 & 3 & 0 \\
\hline \multirow[t]{7}{*}{$7-69$} & + & + & + & - & + & + & + & + & - & + & 45 & 2 & 6 \\
\hline & - & + & + & - & + & + & + & + & - & + & 0 & 1 & 0 \\
\hline & + & - & + & - & + & + & + & + & - & + & 1 & 0 & 0 \\
\hline & + & + & - & - & + & + & + & + & - & + & $\mathbf{3}$ & 0 & 0 \\
\hline & + & + & + & + & - & + & - & + & + & + & 0 & 1 & 0 \\
\hline & + & + & + & - & + & + & - & + & - & + & 1 & 0 & 0 \\
\hline & + & + & + & - & + & + & + & + & + & + & 4 & 0 & 2 \\
\hline \multirow[t]{7}{*}{ Not known } & + & + & + & - & + & + & + & + & - & + & 15 & 3 & 6 \\
\hline & + & - & + & - & + & + & + & + & - & + & 0 & 0 & 1 \\
\hline & + & + & - & - & + & + & + & + & - & + & 4 & 1 & $\mathbf{2}$ \\
\hline & + & + & + & + & - & + & + & + & - & + & 1 & 0 & $\mathbf{1}$ \\
\hline & + & + & + & - & + & + & - & + & - & - & 0 & 0 & 1 \\
\hline & + & + & + & - & + & + & + & + & - & - & 0 & 0 & 1 \\
\hline & + & + & + & - & + & + & + & + & + & + & 9 & 0 & 5 \\
\hline
\end{tabular}

Reactions in heavy type are atypical of the species. 
(169) did not have the uniform behaviour which Hajna \& Damon found in Aerobacter aerogenes. Hajna \& Damon, working only with strains labelled $A$. aerogenes, excluded from their series strains which were anaerogenic or whose IMViC reactions were atypical. The species $K$. pneumoniae is not homogeneous, either culturally or serologically, and an attempt was made to see whether the varying hippurate reactions could be correlated with other atypical biochemical reactions, or with the serotype where this was known (Table 3)

In serotype 1 only 3 strains were biochemically typical of Klebsiella pneumoniae (Table 1) and these were hippurate-negative. Other strains of the serotype were either negative or late positives in the hippurate test; these were atypical in MR, VP, citrate, and/or malonate reactions, and some were anaerogenic (see Table 3). Serotype 3 was unusual in that all members had Mr+ vP-reactions and hydrolysed hippurate in 3-5 days; the majority were gluconate-negative and KCN-negative (Møller, 1954). Only 4 strains of $K$. rhinoscleromatis had been serotyped; these were of type 3 and all were $\mathrm{KCN}$-positive and hippurate-negative. Serotypes 4,5 and 6 each included some $K$. ozaenae strains (hippurate-negative), and most of the NCTC serotype 4 strains were of this species. Neither of the $K$. pneumoniae strains in serotype 5 had reactions strictly typical of the species. In serotype 6 the hippurate and citrate reactions were inversely correlated. The majority of the strains in serotype 2 were hippurate-positive. In contrast to serotype 6, all the hippurate-negatives of serotype 2 were also citrate-negative. With three exceptions, serotypes 7 to 69 were each represented by a single strain, and 58 of these 66 strains were hippurate-positive. Seven members of this large group gave atypical biochemical reactions, but the divergent strains all hydrolysed hippurate. In general, the inability of strains of $K$. pneumoniae to hydrolyse hippurate could not be associated with any other atypical biochemical reaction.

It is thus evident that, except in serotype 3, the hydrolysis of sodium hippurate cannot be correlated with either the serological or biochemical reactions of Klebsiella pneumoniae, and that the test will not distinguish absolutely between this species and Cloaca cloacae and other species of Klebsiella. That this conclusion might have been expected, was implied by the absence from the literature of any reference to the test after Hajna \& Damon's original report; however, it may be of some use for confirming the identity of strains such as those occurring in serotype 3 whose gluconate, MR, VP and cyanide reactions set them apart as a biochemically atypical group.

\section{REFERENCES}

Cowan, S. T. (1955). Biochemical tests for bacterial characterisation. 1. Hippurate test. Int. Bull. bact. Nom. Tax. 5, 97.

Hajna, A. A. \& Damon, S. R. (1934). Differentiation of Aerobacter aerogenes and A. cloacae on the basis of the hydrolysis of sodium hippurate. Amer. J. Hyg. 19, 545.

Møller, V. (1954). Diagnostic use of the Braun KCN test within the Enterobacteriaceae. Acta path. microbiol. scand. 34, 115. 
Munch-Petersen, E. (1940). Studies on bovine mastitis. 1. Study of an experimental herd. Bull. Coun. sci. industr. Res. Aust. 34, 96.

Report (1954). The Enterobacteriaceae Subcommittee of the Nomenclature Committee of the International Association of Microbiologists. Reports on the groups: Salmonella, Shigella, Arizona, Escherichia, Klebsiella (Aerogenes, Aerobacter), Providence (29911 of Stuart et al.). Int. Bull. bact. Nom. Tax. 4, 47.

Stuart, C. A., Wheeler, K. M., Rustigian, R. \& Zimmerman, A. (1943). Biochemical and antigenic relationships of the paracolon bacteria. J. Bact. 45, 101.

Zwikker, J. J. L. (1931). Het aantoonen en het afzonderen van barbitalen bij het taxicologisch onderzoek. Pharm. Weekbl. 68, 975.

(Received 15 March 1957) 